\title{
El modelo sin modelo: El teatro en la filosofía de Jacques Derrida*
}

\author{
Alejandro Fielbaum**
}

\section{Resumen}

El trabajo busca indagar en la importancia filosófica del teatro en el pensamiento de Jacques Derrida, a través del seguimiento de las discusiones que implícita o explícitamente refieren a tales temáticas desde sus primeros textos. Tras exponer lo pensado por Derrida como obra de arte, se indaga en la singularidad de la correspondiente al teatro, en tanto yuxtaposición de repetición y representación. Se busca demostrar que la insistencia derridiana en la imagen teatral ha sido injustamente desconsiderada por los intérpretes, puesto que en tal práctica presta la lógica del préstamo que monta el modelo de la falta de modelo desde el cual se constituiría, espectralmente, el sentido. Así, en tanto mimetología general, la deconstrucción poseería una matriz sugerentemente teatral, desde la cual se busca introducir la lectura derridiana de los textos de Antonin Artaud.

Palabras clave: Jacques Derrida, deconstrucción, teatro

\section{The model without a model: the theater in the phylosophy of Jacques Derrida}

\begin{abstract}
The essay addresses the philosophical weight of theather in the thinking of Jacques Derrida, following the discussions that -in a implicit or explicit way- refer to the issue from his first texts. After the exposition of what Derrida conceives as a work of art, the singularity of the theather is described in terms of the yuxtaposition of repetition and representation. This article intends to show that the derridian insistence in the image of the theater has been wrongly understimated by the interpreters, because that practice borrows the logic of borrowing that affirms the model of the lack of model from where the sense is spectrally constructed. As a general mimetology, deconstruction has a theatrical matrix, from where it is introduced to the derridian interpretation of Antonin Artaud's texts.
\end{abstract}

Keywords: Jacques Derrida, deconstruction, theater

Recibido: 13-05-2011 Aceptado: 06-06-2011

* El presente artículo corresponde a buena parte del cuarto capítulo de la primera sección de la tesis presentada al Instituto de Filosofía de la Pontificia Universidad Católica para obtener el grado de licenciado en Filosofía, durante el primer semestre del 2009. La tesis completa puede hallarse en la Biblioteca de la misma casa de estudios, bajo el título "La última escena: Reflexiones sobre teatro y comunidad en torno a la filosofía de Jacques Derrida".

* Sociólogo y Licenciado en Filosofía, Pontificia Universidad Católica de Chile. Estudiante de Magíster en Estudios Latinoamericanos, Universidad de Chile. afielbaums@gmail.com 
Es el acontecimiento como repetición lo que debemos pensar en el teatro

(Derrida 1991) ${ }^{1}$

Si la metafísica de la presencia se ha erigido desde una lectura representativa del teatro y un malestar por su carácter confuso, la deconstrucción no podrá eludir el enfrentamiento con tales posiciones. Pues la vigencia de tales tensiones no ha desaparecido. El logocentrismo continúa siendo la de un rechazo a la teatralidad, denegando no sólo su escritura sino también cualquier atisbo de teatralidad en su presentación o en la ajena. Derrida es claro al respecto: "¿Y quién podrá pensar que el Platonismo no es actual cuando vemos a Lacan denunciar en la mimesis -en otras palabras, en la desistencia- locura, feminización, histeria? (1998b: 31). Y bien valdría recordar que Lacan no ha sido último heredero de esta larga tradición. Pues la crítica a la simulación seguiría al alero del platonismo (Nancy 2002: 26). Deleuze señala, en efecto, que los impulsores del estructuralismo, y la filosofía que rompe con este movimiento sin restituir lo pensado antes de su decisivo quiebre, deben apelar a un nuevo teatro -o, al menos, a una nueva interpretación de este, que desde una lógica de la multiplicidad tal que ya no se base en las nociones de identidad del autor, el actor y el espectador (1988: 314). Derrida trabajará aquellas temáticas dejando una fuerte influencia en posteriores lecturas que han profundizado al respecto, cuyo momento más potente puede hallarse en el insoslayable trabajo de Lacoue-Labarthe (en particular, 1998). A lo que habría que añadir, suplementariamente, la importancia que la cuestión de la performance y la identidad ha tomado para fundamentales textos surgidos desde la teoría de género y de la poscolonialidad en las respectivas obras de Butler (2003) y Bhabha (2004), ambos desde una clara deuda teórica con el pensamiento de Derrida. También Nancy, quien no se ha referido con tanta frecuencia al tema, ha utilizado el modelo del teatro para pensar la reiteración como sketch o repetición de proposiciones que resultan cada vez desplazadas y remodeladas (1999: xiii), contra la noción de la presentación de sí como exposición de la mismidad. Por otra parte, retoma la imagen de la puesta en escena para describir su constitutiva exposición de la intimidad de los cuerpos (2003: 29). También podemos destacar la reflexión demaniana sobre la mimesis en torno a Kleist (1984). Allí se hallaría el quiebre con el modelo especular para apelar

1 Dado el público del presente escrito, hemos optado por citar traducciones al español de los textos que no han sido escritos en tal idioma. De lo contrario, lo realizamos en inglés o, en último caso, en francés. La responsabilidad por las traducciones en estas dos últimas lenguas es exclusiva de quien firma el presente artículo. 
a cierta hermenéutica de la significación. Así, la apelación al teatro por parte de la deconstrucción no parece irrelevante. No obstante, se ha mencionado escasamente dentro de la amplia gama de libros sobre la obra de Derrida ${ }^{2}$. Incluso un lector tan atento como Jay rápidamente soslaya el asunto, contentándose con indicar -tras remarcar la renuencia derridiana de una mimetologismo, como logocentrismo visual- una nota al pie sobre Lacoue-Labarthe y la extendida sospecha deconstructiva ante el teatro como imitación (2007: 382).

La cuidadosa e inteligente lectura de Rodolphe Gasché parece ser la más incisiva respecto a esta cuestión, aun cuando carezca del desarrollo sistemático con que ha comentado el pensamiento derridiano. Así, remarca que la lógica del myse en abyme, con que suele describirse el devenir inmotivado del signo (por ejemplo, Elam 2004), sigue resultando de una lógica tributaria de nociones de representación que no hacen justicia a lo que ha pensado Derrida (1994: 144). Pues el pensador argelino, ya en sus primeros textos, contrapone la creencia husserliana de una presencia previa a la representación a la concepción de que la significación debe caracterizarse como representación en general, o "representación originaria" (1999: 256). También la lectura derridiana de Platón habría demostrado que la filosofía siempre posee una escena, por impensada o silenciosa que resulte para ella misma. Sólo allí se asegura la buena reproducción y la respectiva expulsión de sus bastardos (1998: 178)², entre ellos, claro está, los hombres cuyo oficio se sitúa sobre, o alrededor de, la escena. De ahí que las infraestructuras que la deconstrucción testimoniaría, en efecto, pueden compararse a escenas o montajes antes que a retratos, pues no eliminan la diferencia, espacialidad o decoración en servicio de nociones de homogeneidad (1986:147). También Peñalver ha descrito el espaciamiento como puesta en escena (1990:82), mientras Clark menciona la utilización del modelo teatral como uno de los principales recursos derridianos en los ensayos sobre literatura (1992: 114). Más recientemente, Weber ha señalado que la iteración puede pensarse como cierta teatralidad (2004: 339).

2 Valga indicar que con ello no queremos decir que la cuestión haya sido nula. Mucho menos, exenta de problemas. Por ejemplo, se ha intentado concluir que desde Derrida la tragedia resulta esencial a la representación y que el teatro, en su mismidad, remite al cuerpo como sufrimiento... (Stocker 2006: 167). Bien habría que oponer esta enigmática idea al desarrollo del concepto de lo cómico en Critchley (1999), en un notable ensayo que no indaga en el pensamiento de Derrida, pero debe considerarse dentro de las tentativas de pensar el tema desde su legado teórico -al igual que el ensayo de Gasché sobre teatro y teoría (2007).

3 Valga añadir que se ha señalado, también justamente, que la lectura realizada de Lévi-Strauss sitúa el problema en la desconsideración en que incurriría de la existencia de la escena previa a la introducción de la escritura empírica (Johnson 1996: 314).

99 
No obstante, pareciese no existir comentario alguno que recoja algo más que aquellos rápidos indicios sobre tal cuestión para centrarse en lo que Derrida ha escrito sobre el arte y el teatro. Este descuido no sólo repite la jerárquica organización temática de la filosofía cuya lógica hipotéticamente buscaría desmontarse ${ }^{4}$, sino que habría contribuido a evitar los malentendidos "textualistas" de la archiescritura como lo que en general se ha llamado, empíricamente, escritura. Impera entonces, por limitado que sea lo que podamos ofrecer, considerar el tema en cuestión. Para aquello, deberemos vincular distintos textos en los que Derrida refiere a un tema que no ha tratado unitariamente en algún texto que devenga central sobre un tema que buscamos rastrear en fuentes varias. Si ya resulta difícil imaginar la extensión que un justo estudio tendría sobre la amplia cantidad de temáticas al respecto, se comprenderá que acá debamos realizar una lectura orientada hacia lo que nos interesa particularmente.

La deconstrucción se halla, para Derrida, atravesada por un cuestionamiento de la noción de obra (2002d: 62). Desconsiderar aquello ha llevado a situar a Derrida bastante más cerca de Gadamer de lo que ambos pareciesen desear, al punto que se ha escrito sobre una supuesta revalorización derridiana del "aquí y ahora" (Clark 2005: 126)5. Al contrario, nos parece que ésta se constituye tanto en el desplazamiento de la unidad del tiempo y el espacio, como en su imposibilidad de circunscribirse a cualquiera de ellos. La obra no sólo se constituye por el decreto decisivo de la separación del cuerpo de la obra del artista, simultáneo al ocultamiento de su producción (1989c: 25), en un movimiento análogo a la distancia requerida por la crítica de la obra (1989c: 11), sino que también por variables formas de legitimación en las que se enmarca o produce como tal. Performativa, produce algo nuevo que no refiere a una realidad previa que representaría. Mas se autoriza desde aquel estado de cosas previo a su aparecer:

Cualquier performativo produce algo, sin duda, hace advenir un acontecimiento, pero lo que hace de este modo llegar no es

4 En especial si consideramos que tras la espléndida introducción de Gasché (o, en español, el buen trabajo existente en de Peretti, (1989) la necesidad de introducción estrictamente filosófica a Derrida ya se ha realizado -y que la mayoría de los comentarios tampoco buscan aquello.

5 En efecto, la importancia otorgada por Gadamer a la obra difiere radicalmente a las consideraciones derridianas de la misma. Así, señala que quien representa revincula allí su nueva identidad, presentando una nueva verdad emergente mediante una obra que se cumple completa y unitariamente, sin reserva alguna ni arbitrariedad en su ejecución. Aquello no sólo le permitirá mantener, desde tal figura, una concepción sumamente operante de la obra en La actualidad de lo bello (1991), sino también de la comunidad lograda en tal exposición teatral, como verdadera comunión (1977: 178), lo que puede contraponerse al carácter eminentemente disperso que describiremos en Derrida. 
necesariamente una obra, y siempre debe ser autorizado por un conjunto de convenciones o de ficciones convencionales, de "como si" en los que se funda y se pone de acuerdo una comunidad institucional. (2002d: 39).

Ahora bien, su particularidad no deja intactas aquellas estructuras en las cuales se ha clasificado. La indecidible relación que una obra porta con aquellos archivos es parte de su constitución. Por lo tanto una obra es, en cierta medida, su contexto: Se lee en un contexto, pero al mismo tiempo lo produce o desplaza -desplazándose, por cierto, a sí misma (2001a: 15)-. Pues tal mutabilidad afectará también la supuesta identidad de las obras. De ahí que pueda considerarse, simultáneamente, como una experiencia tanto de contexto como de dislocación (1994). Las estrategias y negociaciones en las cuales se situará la obra no le pueden venir adscritas de antemano, pero tampoco la obra deja de inscribirse en los mismos conflictos por su interpretación. Es decir, su propia constitución permite que las múltiples lecturas que ejercen de ella descontituyan toda pretensión de mismidad. Así, incluso la más silenciosa de las obras, siempre resulta locuaz en lo pertinente a su posesión de infinitos discursos virtuales. Siempre pueden, por tanto, ser recibidas o interpretadas como discursos en potencia. Nacida en su exposición, ningún gesto podría recogerla hacia una simultaneidad que agotase su exposición de sentido: Ninguna presencia se funda en tal aparecer, y ninguna comunidad en tal observación. De ahí la precisión de la crítica que De Man ha realizado a la estética de la recepción (1990), en particular, a Jauss. Pues aquí se halla la irreductible diferencia entre la deconstrucción y la Escuela de Constanza, cuya noción de obra sigue heredando su concepción primeramente unitaria. Es por eso que tal línea interpretativa pueda ser, menos problemáticamente, considerada una estética. Al contrario, la fragmentariedad de la observación pensada por la deconstrucción torna difícil tal apelativo. La obra se halla situada en un contexto estructuralmente indeterminado, dada la imposibilidad de su cierre o saturación. Huelga decir que no se trata ni de una dialéctica, ni de un sistema social del arte cuya regla o modo de operación determinante pueda fundamentar todas sus operaciones. Pues cualquier intento de demarcación padece la diseminación. Ni siquiera las tipologías en las cuales podría encuadrarse la obra resultan seguras:

Como el significado de 'género' o 'estilo', o como el 'canon' o el de la unidad de una 'obra'; el significado de versión, y de la unidad de una versión, es invadido, excedido, por esa estructura de la invaginación: no solamente cancelado o invalidado, sino 
que expuesto en la precariedad de su efecto, la fragilidad de los artículos convencionales que provisionalmente lo garantizan (2003a: 104).

En efecto, ante distintos lectores en un determinado espacio de exposición no sólo difiere la consideración de las obras de arte, sino de lo comprendido como arte y sus formas de legitimación y encuadre. En tal sentido, al situarse ante el arte se padecería la indeterminación que constituye al sentido. Así, el arte remarca cierta experiencia de la lengua o del trazo como tales. Esto es, como desdoblamiento que se padece como tal desde cualquiera de sus momentos de producción o recepción. Pues la iteración, claro está, no resulta monopolio de lo considerado como arte sino que afecta, constitutivamente, cualquier enunciado. La diferencia específica del arte se sitúa en que, allí, la locura que afecta y produce todo recurso lingüístico es parte de lo que el ejercicio del lenguaje despliega. El maridaje entre arte y filosofía contemporánea se establece, en efecto, desde el mutuo interés de exponer los límites de sus propios recursos de exposición. Su oxímoron es el de dar con la extrañeza que lo asfixia, vincularse a un objeto que resiste a cualquier transparencia comunicativa. Es decir, la familiaridad con el acoger la incontrolable espectralidad que asedia cualquiera de sus manifestaciones,

Cabe, naturalmente, traducirla en pérdida ineluctable del origen.

En el duelo, la experiencia del duelo, el paso también de su límite, sería pues difícil ver una ley que domine un tema o un género. Es la experiencia, y como tal, para la poesía, la literatura, el arte mismo (2002c: 89).

Se trata, entonces, de experimentar la lengua en su pura impureza, su traducible intraductibilidad. El carácter móvil e impredecible de la obra impide adscribirla unitaria y definitivamente a un idioma dado. Y en tal movimiento iterativo deja impresa -desde aquella constitutiva carencia de unidad-sus evanescentes marcas allí donde se haya, vanamente, situado. Derrida considera que la obra dota, desde su exterioridad, al estado de lengua una desconocida posibilidad, mas con un futuro incierto que tornará imposible pensar cualquier linealidad fuera del quehacer de su artificio: "¿Qué es una obra? Crear una obra es dar un nuevo cuerpo a la lengua, dar a la lengua un cuerpo tal que esta verdad de la lengua aparezca allí como tal, aparezca y desaparezca, aparezca en retirada elíptica" (2001c). Claro está, el movimiento descrito torna imposible el tono lógico u ontológico de la pregunta recién citada. Esta restancia como destinerrancia-y viceversa-, junto con impedir un origen pleno o devenir teleológico, impide también la inexistencia de marca

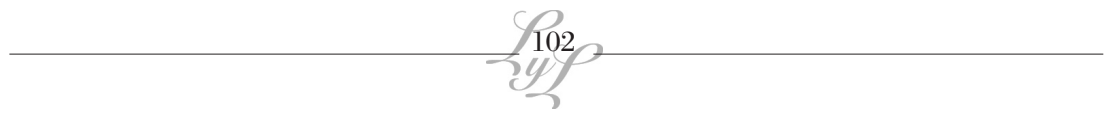


alguna de su paso. Bien se ha descrito la deconstrucción desde aquel movimiento de lo retirado que permanece desde aquel retiro, señalando que siempre algo -de la obra- "sobra" (Hall 1999: 138). Ésta siempre excede su supuesta forma -la cual, no obstante, la configura como tal-. Obra, así, en su constitutiva inestabilidad. Bien recuerda Nancy que para Derrida la locura será el exceso de obra (2007:20) -en contraposición a Foucault, para quien la locura se cifraba desde su ausencia (1976)-. Indecidible devenir que ninguna institucionalidad puede controlar, puesto que toda regla se constituye y desconstituye en este movimiento al cual no se añade ni precede. Sólo mantiene una signatura -aunque sea la del anonimato.

Allí pareciera cifrarse, en toda su inestabilidad, su diferencia formal como exigencia de fáctica consideración de su trazo como arte. Irónicamente, el arte se presenta como tal remitiendo a quien expone su ausencia. Lo importante pareciera ser, por lo tanto, que se testimonie lo vivenciado como motivada invitación a la experiencia por parte de quien sólo podría lograr tal éxito en el fracaso de su presencia. Pues la firma adviene en una débil retirada que requiere de la contrafirma producida por el reconocimiento ajeno (1994). Se sitúa entonces desde la prestada y necesaria identidad de un artista que ya no podrá pensarse desde la metáfora filial y la constelación circundante de conceptos montada desde aquella paternidad. Por el contrario, la obra no traduce anterioridad alguna ni deja traducción posterior. Esto no invalida la firma, sino que sólo despliega rigurosamente su ley de incompleta transmisión -de la necesidad de la lectura como cierre, que nada cierra, imperante incluso en la autobiografía (Moreiras 1999: 221)-. En efecto, casi definiendo, Derrida señala lo que entiende por obra:

algo que queda, que es absolutamente intraducible, que porta una firma... en cualquier caso, algo que tiene un lugar, una cierta consistencia que es grabada, a la cual se puede retornar, que puede ser repetido en distinto contexto, que puede ser leída en el futuro en un contexto en el cual las condiciones de la lectura han cambiado (2001a: 14).

Lo particular del teatro respecto de otras prácticas artísticas es que yuxtapone representación y repetición -mientras la mayoría toma la primera operación, generalmente, contra la segunda-. Aquello se mantiene aun si, contra otras artes, buscase liberarse de la representación. Así, hablar de representación en el teatro resulta tan redundante como problemático, dada la dificultad de derivar cada presentación de alguna anterior: 
En el orden estético, se puede hablar de representación en el sentido de la sustitución mimética, especialmente de las artes llamadas plásticas y, de manera más problemática, de representación teatral en un sentido que no es forzosamente ni únicamente reproductivo o repetitivo sino para nombrar la representación (1989a: 82).

Curiosamente, tal primacía representativa no parece diferenciarse radicalmente de las distintas consideraciones sobre el teatro desde distintos textos decisivos en la tradición logocéntrica. Y es que la descripción que brinda Derrida no difiere considerablemente al ubicuo lugar que la historia de la filosofía le ha atribuido a tal práctica. Al menos, en lo que refiere a los filosofemas asociados a la teatralidad. Señala, por ejemplo, que el hombre de teatro obra la obra, la cual resulta inexistente antes de su puesta en obra (1991). El drama acontece en la representación, en la cual los distintos elementos se ordenan en función del montaje. Aquello se extiende, incluso, a las personas que allí actúan. Su carácter de mera imagen es tal que incluso con marionetas -pensadas como prótesis, simulacro, fetiche- se puede hacer uno (2005: 111). Ninguna autonomía resulta allí posible, ni tampoco certeza alguna. Y también considera que todo el problema de la percepción teatral se halla atravesado por el confuso estatuto de la creencia: "¿Pero qué es creer? He ahí la cuestión planteada que está puesta en escena o asoleada por el teatro” (1991).

El quiebre se halla en que, para Derrida, el registro teatral no resulta una mera excepcionalidad, sino que brindará el modelo para pensar, precisamente, la falta de modelo en las formas discursivas de montar toda prometida realidad. Nada nos autoriza aquí, por cierto, a hablar rápidamente del teatro como ejemplo, símbolo, analogía o metáfora. Pues tales imágenes lógicas o retóricas quedan, también, puestas en entredicho. Mantengamos, pues, la enunciación de " $\mathrm{x} \sin \mathrm{x}$ ". Derrida ha confesado, reiteradamente, su cercanía a aquella lógica de la sustracción ideada por Blanchot. Aquí recurrimos a ella para describir aquello como modelo sin modelo -de la falta de modelo-. Claro está, no se trata de una inversión del pensar metafísico, sino de pensar lo expulsado que siempre ha debido subyacer para mantener el régimen de enunciación que los expulsa. Ese tenso lazo posee tremenda importancia. Pues la turbulenta e insistente afinidad entre la filosofía y el teatro quizás marca, señala explícita y sorprendentemente, la historia de Occidente (1991). Al menos, pareciese entreverse, de su filosofía y de los discursos que allí se han construido. En efecto, señala que la lógica subyacente a la crítica de la máscara o el simulacro -en nombre de una verdad originaria que de- 
nuncia la técnica- permanece imperturbablemente de Platón a Heidegger (2000: 42). Pues esta disyunción ha debido remarcarse constantemente para conjurar contactos demasiado estrechos que pudiesen testimoniar afinidad electiva alguna.

Pues nada menos que el gran gesto metafísico sería la búsqueda de cierta realidad por imitar, previa a la imitación (1977: 93). Esta se establece desde la descripción de aquella presencia primordial que permite distinguir entre el antes y después de la representación. Acaso, como un dentro y fuera del teatro. En efecto, la metafísica de la presencia se establece subordinando a la escritura comprendida como añadida representación (1989a: 92). Mientras que, en el teatro, la representación no puede ser pensada como prescindible accidentalidad. El desdoblamiento de aquel improcedente proceder que presenta una presencia que jamás estuvo antes de aquellas operaciones, ni se mantiene como tal durante la misma, sutura, a contrapelo, toda la historia de la filosofía -en tanto pertenencia al orden de la representación (1997b:36). Derrida, en efecto, escribirá representación junto a retraso y reserva como indicaciones del efecto de la diferencia (1998a: 43). Y es que acaso el movimiento de la teatralidad puede considerarse otro de los nombres del efecto de diferimiento de la archi-escritura, en tanto espaciamiento de todo trazo que, repetido, difiere de sí. Nada se habría entendido si se intentase dirimir aquí si teatro debe referir finalmente a la literatura, o viceversa, en búsqueda de algo previo y más verdadero. Ya que precisamente se trata de la falta de aquel origen que torna suplementaria toda propiedad a otras tantas. En efecto, describe como locura abisal -esto es, invisible e irrepresentable figura de un comienzo- a una escena de las escenas, escenarios, representaciones (2003a: 94). He ahí la experiencia de la cesura. La consecuencia de lo descrito no es la invasión de la vida por parte del teatro o una inversión en la cual esto último pasa a ser más verdadero, sino que lo que su práctica indica presta su espectral modelo para comprender la infinita estructura de préstamo mediante el cual se constituye el sentido. Según Derrida, en efecto, los movimientos iterativos comprenden a la literatura y el teatro, mas no dependen de su positiva institución para ser considerados. Pues su efecto trasciende cualquiera de sus concretos devenires. Al punto que cuestiona la tajante distinción entre aquellas dimensiones y la vida obviamente real: "icomo si la literatura, teatro, engaño, infidelidad, hipocresía, infortunio, parasitismo y la simulación de la vida real no fuesen parte de la vida real!" (1977: 90).

El movimiento aquí pensado resulta irreductible a alguna previa lógica mimética, pues resulta imposible establecer un comienzo en el 
proceso de imitación. O un criterio estable, u objetivo, para distinguir la calidad de la misma. Todo enunciado, en efecto, puede desviar las formas hegemónicas de enunciación de aquella estructura sin por ello dejar de confirmar lo antes escrito. Pues ninguna crítica a las estructuras que posibilitan el sentido puede asegurar situarse puramente fuera de las mismas. Por el contrario, no pueden sino negociar, trabajar sin jamás destronar totalmente sus límites. Pues la promesa de la presencia que advendría tras aquellos márgenes resulta, inmemorialmente, inventada y contenida por aquel orden. Bien describe Ticio Escobar esta falta de salida: "supuesto en su mismo juego tramposo, el gesto que critica la representación es enunciado desde adentro de la escena y, por eso, termina por afianzarla" (2004: 145). Pues el movimiento del lenguaje se halla siempre activado por múltiples técnicas de teatralidad dentro de la cual se inscribe la pretensión de la ausencia de ella -De Man es claro al respecto al señalar que la expresión, sin mediación, es imposible (1991: 13). Ninguna plenitud puede pensarse en esta ley de la iterabilidad que parte por repetirse a sí misma infinitamente. De esta forma, se piensa todo enunciado como potencialmente imitable, desde una necesaria obliteración en la que todo resulta reproducible, parasitable, impuro (Derrida 1977: 90). Stanley Fish ha remarcado esta imposibilidad de distinguir claramente entre la presentación auténtica y la posible desviación de aquella presencia desde la anécdota de hallar ciertos saludos escritos por el autor de un libro, los que ni siquiera la aparición del mismo podría determinar establemente. No casualmente, recurrirá a la jerga teatral para describir tan incierta experiencia:

Si Derrida estuviera delante de mí, con su libro, su mensaje y su "presencia", yo seguiría en la situación del espectador de teatro, no infiriendo su intención y su significación directamente de sus palabras, sino a través del filtro, ya colocado, de lo que presumo que son sus propósitos, fines, intereses, etcétera (2002: 76).

El doble sentido que Derrida nota en la noción de representación, como delegación y como espectáculo (1984:24), no podría escindirse. Ya que el espaciamiento propio del envío requiere de una suplementaria, jamás idéntica, reescenificación para enunciar en nombre de otro. Y, sin tal autorización heterónoma, nada podría exponerse. Y aquella sería, para Derrida, la única forma de enunciar: En nombre de otro que no se presenta, asediando infinitamente. Las formas del espectáculo siempre se hallan delegadas por tal suplantamiento. Derrida confiesa que las distintas descripciones que ha otorgado al movimiento de la escritura parecen asemejarse a un montaje (2001b). Nada se comprendería allí sin la cita 
y la serie. Lo que, claro está, impide la reunión del presente consigo. El concepto de representación se halla habitado por una repetición que siempre desdobla la identidad que busca representar (1989a:92). El teatro de Daniel Mesguich daría cuenta de aquella cuestión. Éste permite pensar una repetición que ya no prepara la primera, por el contrario. Por el contrario, allí se concibe ya una repetición que divide y excava la presencia que hace surgir. Pero no como modelo o imagen de lo presente en otro lugar sino como presencia única y repetida. Este constitutivo diferimiento no resulta una negativa destrucción de la obra. Sino que, deconstruida, resitúa sus posibilidades desde su imposible plenitud. Como si pudiésemos escribir: La obra siempre y nunca se estrena -es decir, siempre resulta nueva puesto que jamás lo fue, desde un sentido de novedad que ya no remitirá a una fundante venida a la presencia completa de su anterior inexistencia. Puesto que, lejos de debilitarla, afirma tan curiosa lógica:

esta estructura de repetición intensifica, por el contrario, la experiencia de la irremplazable primera vez, del único acontecimiento que se produce cada vez que sobre el escenario una puesta en escena pone en obra y que se produce el acto teatral (1991).

Esta particular forma de acontecer en el teatro será, para Derrida, la condición de posibilidad de todo acontecimiento. Es decir, su imposibilidad. Pues nada podría acontecer en el lenguaje -allí donde se acontece- desde la unicidad que promete. El carácter imprevisible del acontecimiento lo es también de su propio futuro, pues pierde su propiedad entre infinitas, constitutivas, mediaciones que lo harán -como tal-imposible. Puesto que el sentido opera desde la repetición, este sólo se torna legible desde los marcos de repetición del contexto que, inopinadamente, podrá descuadrar. Todo acontecimiento, por tanto, se ve posibilitado por la repetición que lo neutraliza como absoluta novedad exterior (2004). Ninguna exterioridad adviene puramente, y ninguna interioridad se mantiene inmune del exterior que, expulsado para ser constituido, no deja de asediarlo desde su flaca interioridad:

el acontecimiento no puede aparecerse como acontecimiento cuando aparece, salvo que ya sea repetible en su unicidad. Es difícil captar la idea de unicidad como inmediatamente iterable, o singularidad como inmediatamente comprometida con la substitución... Existe iterabilidad y retorno en absoluta unicidad y enunciación singular, lo que significa que lo arribado o el arribante -o el venir del evento inaugural- sólo puede ser deseado como un retorno espectral (2007: 134). 
Podemos hallar testimonio en la escritura derridiana de tal importancia del teatro. Por ejemplo, respecto al reparto filosófico. Derrida lo ha llamado recientemente una dramaturgia, desde su pretensión de clasificación y universalización de saberes varios (2002b: 62). No se trata, en efecto, de un cuestionamiento del hecho de tomar un rol, sino de la-contingente y responsable-posición tomada dentro de un reparto discursivo cuyas determinaciones espaciales y temporales no hacen sino reforzar la potencia del modelo que aquí comentamos. La distinción entre actores y sujetos, en efecto, remite a demarcaciones sociales antes que a atributos de quien se expresa públicamente. E incluso aquella descripción se asume como realizada dentro de la misma manera teatral:

Aunque en este momento, aquí, no hagamos teatro en sentido convencional, todo esto es bastante teatral. No sólo porque estamos sobre un escenario, ante un público, sino porque todo esto es palabra pública, un guion con un tiempo limitado, aproximadamente el tiempo habitual de una obra habitual, una puesta en escena, una visibilidad estructurada con vistas a un espectáculo y a una difusión más o menos mediatizada. Y aunque casi ninguno de nosotros - digo casi- sea actor en el sentido estricto y profesional del término, todos somos actores, cada uno a su manera, actores públicamente conocidos, actores y personajes reconocidos, entre otras cosas por su palabra política, por el papel político inscrito o prescrito en su partitura (2003b: 177) ${ }^{6}$.

Tal lectura de sí parece clara para ratificar la virtualidad que socava la propia exposición. Pues el sujeto, para Derrida, sólo se presenta "como si" (Trujillo 2005: 308). Mas no hay que especular mucho para pensar aquello. Pues su insistencia en el modelo teatral se halla en los textos sobre grandes referentes del logocentrismo. En particular, a partir de la cuestión de la representación. Ya en La voz y el fenómeno señala que la filosofía de la presencia borra el signo derivándolo, en un gesto que suprime la reproducción y repetición que habitan la presencia (1995c: 101). Mas tal estructura, no casualmente analogada a la escena, configura toda posibilidad de la historia o metafísica de la cual resulta expulsada:

No sabemos, pues, si lo que se ha presentado siempre como representación derivada y modificada de la simple presentación....

6 También las tensiones internas y los despliegues políticos del feminismo han sido llamados un teatro (Derrida \& Christie 1997: 25). La misma imagen es utilizada en dos ocasiones al comentar el despliegue de la cuestión del espíritu en el desarrollo de la obra de Heidegger, ocupando los apelativos de dramaturgia o personaje (1987: 55, 109). 
no 'es', en un sentido necesariamente pero novedosamente ahistórico, más 'viejo' que la presencia y el sistema de la verdad, más viejo que la 'historia'.... antes incluso que se distinga entre su literalidad 'sensible' y su puesta en escena metafórica en toda la historia de la filosofía... si lo que llamamos viejos nombres de fuerza y diferencia no es más 'antiguo' que lo 'originario' (1995c: 166).

Sobre Freud, describe de qué forma el necesario rodeo por la representación torna imposible una noción completa de vida. Y tales mediaciones producirían espectrales imitaciones que doblan a un original del cual no puede distinguirse. No queda sino pasar por la técnica, pues todo se ha posibilitado por ella. Incluso la memoria psíquica, ya deconstruida, no logra concebirse previa a aquellos dispositivos en los cuales la presencia pasa a ser un efecto derivado:

lo que tenía que funcionar por sí solo era lo psíquico y no su imitación o su representación mecánica. Ésta no vive. La representación es la muerte. Lo cual se vuelve enseguida en la proposición siguiente: la muerte (no) es (más que) representación. Pero está unida a la vida y al presente viviente que repite originariamente.

(1989b: 311)

Más clara resulta la cuestión, por cierto, en los comentarios que Derrida ha realizado ya directamente sobre la mimesis. No habría que haber esperado a Aristóteles para asumir que la mimesis habita la interioridad de quien actúa (1998: 276). Pues ya Platón sintomatizaría el malestar contra esta constitutiva reproductibilidad que disemina la esencialidad. Pensaría, precisamente, ese modelo sin modelo en el que, positivamente, la idealidad se desidentifica:

Este desdoblamiento se relaciona con la esencia, sin esencia, de la mimesis, con el hecho de que no es, que no existe, pero desiste, y que esto no implica nada negativo... (ya no) definida como 'declinación', 'inestabilidad', accidental 'desinstalación' o 'caída' que le ha acontecido a la verdad (1998b: 21).

El saber de la imposibilidad de un saber concebido desde la presencia, pensable desde la teatralidad, se situaría entonces desde el, falto de inicio, inicio. Derrida, en efecto, llegará a una conclusión similar a Lacoue-Labarthe. Este último, por ello, se ha referido al pensamiento del argelino como una mimetología general (1997: 76). Allí nada escapa a la ley de imitaciones que nunca dejan de diferenciarse de sí. Aquello invalidaría la lógica del sujeto, dada su manifestación de su intimidad 
como dehiscencia (2002: 103). El desvío del platonismo realizado por la deconstrucción remarca, de esta forma, su radicalidad en pensar desenraizadamente:

Y así cuando se desea subrayar que la mimesis no tiene el (caído) estatuto de una falla o derivación accidental, se está tentado a llamarla, contra Platón, 'originaria' -aunque aclarando que la cualidad de ser originario es incompatible con la de mimesis (Derrida 1998b: 22).

Más discutible aún resulta la constante omisión del tópico de la teatralidad en Derrida si se considera que los textos derridianos que suelen considerarse más importantes otorgan comentarios directos sobre el teatro. Podemos hallar ejemplos desde sus primeras publicaciones hasta ideas recientes -por ejemplo, el enviarse de sí a sí, en Joyce, como escena (2002a: 116)-. Ya en De la Gramatología señala que el logocentrismo parte desde una presencia imperturbable por la representación (1986: 129), que se contrapondrá al movimiento de la escritura como juego de representación que hurta la presencia (1986: 185). El origen se torna inasible, y la presencia una despresentación. Toda inmediatez se hallaría derivada por infinitas mediaciones cuya plenitud, en efecto, impiden:

la representación en abismo de la presencia no es un accidente de la presencia, el deseo de la presencia nace, al contrario, del abismo de la representación, de la representación de la representación, etc. (1986: 208).

Aquello sería aún más patente en la descripción de la economía del suplemento en Rousseau. Allí se remarca que el teatro se halla totalmente trabajado por el mal de la representación. En ningún otro punto de su obra la corrupción aparecería tan puramente (1986: 383). La secundarización de la escritura es también la del teatro y todo lo asociado a su imposible ontología. Insistimos que no se trata aquí de demostrar que algo así como una presencia teatral previa a los procesos de representación, sino que lo que tradicionalmente ha exigido ser pensado desde la existencia del teatro daría cuenta de la estructura que atraviesa todo el proceso de significación del que se ha buscado expulsarlo. Así, la plenitud del habla y la vida a la que se asocia queda desconstituida por el teatro. La vida en su mismidad, y viceversa, se pierde en una espacializada realidad no puede ser sino un constitutivo, suicida, diferir: "Las artes del espacio llevan la muerte en sí" (1986: 249).

También en La diseminación se encuentran constantes referencias a la teatralidad. La Farmacia de Platón insiste en el carácter teatral de la

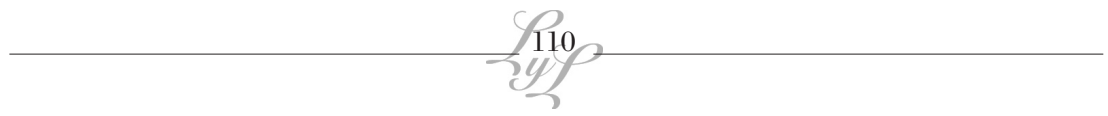


escritura en Platón. La lectura del Fedro demuestra que la denostada escritura se piensa como escenificación, y la imitación como desnaturalización que ocurre a la verdad: "la imita perfectamente porque ya no la imita del todo. Pues la imitación afirma y agudiza su esencia al desaparecer. Su esencia es su no-esencia. Y ninguna dialéctica puede resumir esa inadecuación consigo" (1995a: 210). Y así como la verdad debe pasar por la repetición para constituirse como ilusión de presencia previa a la repetición, Platón deberá teatralizar para dar cuenta de dicha expulsión de la teatralidad. Su farmacia, en efecto, es llamada un teatro (1995a: 216). La diferencia entre Platón y Mallarmé no sólo remite a la distinta consideración que ambos otorgan a la escritura, sino también a la cuestión de la imitación teatral que ya prepara la octava nota al pie del ensayo sobre el poeta francés. Allí, se señala que el concepto de mimesis en Platón remite a una invalidada duplicación suplementaria de un ser que no la requiere. Mímica no podría sino contrariar aquello:

no hay imitación. El Mimo no imita nada. Y en primer lugar no imita. No hay nada antes de la escritura de sus gestos. Nada le es prescrito. Ningún presente habrá precedido ni vigilado el trazado de su escritura... El Mimo no sigue ningún libreto preestablecido, ningún programa venido de otra parte. No es que improvise y se abandone a la espontaneidad: simplemente, no obedece a ningún orden verbal (1995b: 293).

Tal performance se modela a sí misma desde un desdoblamiento que socava, simultáneamente, su propio modelo. Se erige desde una lectura necesariamente de un texto que, por carecer de referencia, obliga a la imposible decisión que lo reescribe desde la figura del mimo cuyo ser es la simulación. Y no sólo de dos personajes, sino también de dos sexos distintos. No puede ya tratarse de un actor alienado o mentiroso, puesto que carece de interioridad previa a la cual renunciar. O bien de un texto al cual pueda subordinarse pasiva o conclusivamente. Números, por su parte, es un texto que se pone a sí dentro de su escena -lo que siempre ha trabajado al texto en general-. Se trata de una injustificable organización teatral que socava todas las figuras y espacios asociados a la imagen teatral:

los antiguos fantasmas denominados el autor, el lector, el director, el maquinista, el actor, los personajes, el espectador, etc., no tienen ya un lugar único, único y fijo (sala, escenario, pasillos, etc.) por ellos mismos asignados, más que en la representación que de ello hacen y de la que hay que dar razón (1995b: 445). 
Es decir, el teatro se piensa como escenas sin límite determinable ni realidad previa a la cual referir, internamente constituido desde divisiones móviles que anulan cualquier prescripción espacial o voz ajena que pudiese reunir la dispersión. La diferencia con Platón se sitúa en su descreencia en alguna presencia previa a la cual pudiera, la actuación, remitir. En efecto, años más tarde Derrida dirá que Mallarmé rompe con la lógica filosófica de la representación existente en Platón y Aristóteles (1997a: 69), pues mantiene la estructura fantasmal del simulacro como copia de otra copia, mas sin modelo alguno ontológico o dialéctico que pudiese servir como su comienzo. La operación del mimo es la de no creer, ni siquiera, en ser un mimo -si con ello se pensase en identidad alguna-. Aquella constitutiva pluralidad no debe pensarse como inadecuación o descalce. Puesto que, positivamente, carece de propiedad a la cual añadir gestos u oropeles. Nuevamente, el teatro sirve aquí de espectral imagen, ya que "no muestra "las cosas tal cual", no las representa más, muestra una representación, se muestra como ficción, muestra menos las cosas o su imagen que muestra una máquina" (1995b: 356). Es el modelo, entonces, de la prótesis desde la cual puede surgir la siempre inestable significación.

Lo anterior no puede pensarse desde los binomios logocéntricos desde los cuales se consideró el teatro. Claro está, no se trata de una inversión en la cual el simulador pasa a ser más real u original que quien no se dedique a ello, sino que todo se halla atravesado por la descrita ley de la iterabilidad. La cuestión requiere ser repensada desde una perspectiva deconstructiva en la cual las antiguas separaciones y subordinaciones ya no puedan resultar tan claras. En particular, la cuestión de la representación requiere ser aquí interrogada más detenidamente. Ya que si no puede hallarse una presencia previa ni una identidad a la iteración resulta problemático tanto afirmar como negar la representación. No sólo una crítica a esta figura del logocentrismo que volviese a alguna figura de presencia resultaría ingenua (1989 a: 95), sino también algún idealismo en el cual se diluyan las diferencias de las distintas series imitativas. Será necesario, por tanto, que Derrida reflexione sobre esta cuestión desde sus primeros textos, para lo cual deconstruirá al más influyente pensador sobre el teatro en el pensamiento de su época: Antonin Artaud. Nos referimos, claro está, a los ensayos La palabra soplada y El teatro de la crueldad y la clausura de la representación, cuya lectura hemos intentado preparar a lo largo de las presentes páginas. Es claro que carecemos de espacio para abordar aquí tal empresa, pero también que lo expuesto exige considerar tal tarea con mucha mayor importancia que la que se 
ha la otorgado a tales estudios. Nada autoriza, entonces, a excluirlos de la preocupación estrictamente filosófica derridiana. Al contrario, obliga a abrir tal preocupación desde la filosofía hacia lo que, excediéndola, reconfigura su deseo a través de la necesaria e imposible mediación teatral, cuyo asedio a la metafísica exigirá, rigurosamente, la preocupación por lo que allí acontece.

\section{Bibliografía}

Bhabha, H. (2004). "Of mimicry and man: The ambivalence of colonial discourse". En The location of culture. Nueva York: Routledge.

Butler, J. (2003). Cuerpos que importan. Sobre los límites materiales y discursivos del sexo. Buenos Aires: Paidós.

Clark, T. (1994). Heidegger, Blanchot. Sources of Derrida's notion and practice of literature. Nueva York: Cambridge University Press.

(2005). The poetics of singularity. The Counter-Culturalist Turn in Heidegger, Derrida, Blanchot and the later Gaddamer. Edimburgo: Edinburg University Press.

Critchley, S. (1999). "Comedy and Finitude: Displacing the Tragic-Heroic Paradigm in Philosophy and Psychoanalysis". En Ethics-Politics-Subjectivity. Essays on Derrida, Lévinas and Contemporary French Thought. Londres: Verso.

Deleuze, G. (1988). Diferencia y repetición. Madrid: Júcar.

Derrida, J. (1977). Limited Inc. Evanson; Northwester University Press.

(1984). "Kant: El conflicto de las facultades". En La filosofía como institución. Barcelona: Juan Granica.

(1986). De la gramatología. Buenos Aires: Siglo Veintiuno.

(1987). Del espiritu. Heidegger y la pregunta. Valencia: PreTextos.

(1989). "Envíos". En La desconstrucción en las fronteras de la filosofía: la retirada de la metáfora. Barcelona; Paidós.

(1989). "Freud y la escena de la escritura". En La escritura y la diferencia. Barcelona: Anthropos.

(1989). "Fuerza y significación". En La escritura y la diferencia. Barcelona: Anthropos. 
El modelo sin modelo. El teatro en la filosofía de Jacques Derrida / Alejandro Fielbaum

(1991). "El sacrificio". Intervención realizada el 20 de octubre de 1991 en el Encuentro "Lo irrepresentable, el secreto, la noche, lo forcluído". La traducción al español que utilizamos, realizada por Cristóbal Durán, puede hallarse en www.jacquesderrida.com.ar

(1994). "Las artes del espacio". Disponible en www.jacquesderrida. com.ar

(1995). "La Farmacia de Platón". En La diseminación. F Madrid, Fundamentos, 1995.

(1995). "La diseminación". En La diseminación. F Madrid, Fundamentos, 1995.

(1995). La voz y el fenómeno. Valencia: Pre-Textos.

(1997). "Mallarmé". En Cómo no hablar y otros textos. Madrid: Anthropos.

(1997). "Resistencias". En Resistencia del psicoanálisis. Buenos Aires: Paidós.

\& McDonald, C. "Choreographies: Interview". En (Holland, Nancy Editora), Feminist interpretations of Jacques Derrida. Pennsylvania: Pennsylvania State Universitty Press.

(1998). "La différance". En Márgenes de la filosofía. Madrid: Cátedra.

(1998). "Introduction: Desistance". En Lacoue-Labarthe, Philippe. Typography. Mimesis, Philosophy, Politicss. Stanford: Stanford University Press.

(1998). "La mitología blanca". En Márgenes de la filosofía. Madrid: Cátedra.

(2000). Dar la muerte. Paidós: Barcelona.

\& Ferraris, M. (2001). A taste for the secret. Cambridge: Polity. (2001). "El cine y sus fantasmas. Entrevista con Antoine de Baecque y Thierry Jousse". Disponible en www. jacquesderrida.com.ar

(2001). "La lengua no pertenece" (Entrevista con Èvelyne Grossmann). En Diario de Poesía, nº 58.

(2002). "Dos palabras para Joyce". En Ulises gramófono. Dos palabras para Joyce. Buenos Aires: Tres haches.

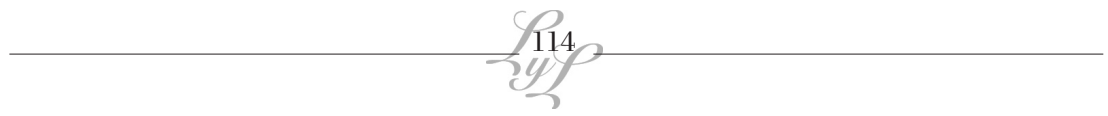


(2002). "Privilege: Justificatory Title and Introductory Remarks". En Who's afraid of philosophy? Right to Philosophy I. Stanford: Stanford University Press.

(2002). Schibboleth. Para Paul Celan. Madrid: Arena.

(2002). Universidad sin condición. Madrid: Trotta.

(2003). "Sobrevivir". En (VVAA), Deconstrucción y crítica. México

D.F.: Siglo veintiuno editores.

(2003). "Marx no es un don nadie". En (De Peretti, Cristina, Comp.) Espectrografias. (Desde Marx y Derrida). Trotta: Madrid.

(2004). "Autoinmunidad: suicidios simbólicos y reales". En Borradori, Giovanna, La filosofía en una época del terror. Entrevistas con Jurgen Habermas y Jacques Derrida. Buenos Aires: Taurus.

(2005). "Majesties". En Sovereignties in Question. The Poetics of Paul Celan. Nueva York: Fordham University Press.

(2007). "A Certain Impossible Possibility of Saying the Event". En (Mitchell, W. J. T. \& Davidon, A. Editores), The Late Derrida. Chicago: University of Chicago Press.

Elam, D. (1994). Feminism and deconstruction: Ms. en abyme. Londres: Routledge.

Escobar, T. (2004). "El arte fuera de sí. (Veintisiete fragmentos sobre la paradoja de la representación y una pregunta sobre el tema del aura)". En El arte fuera de sí. Asunción: Fondec.

Fish, S. (2002). "Con los saludos del autor: Reflexiones sobre Austin y Derrida". En Práctica sin teoría: retórica y cambio en la vida institucional. Barcelona: Destino.

Foucault, M. (1976). Historia de la locura en la época clásica. México D.F.: Fondo de Cultura Económica.

Gadamer, H-G. (1977). Verdad y método. Fundamentos de una hermenéutica filosófica. Salamanca: Sígueme.

(1991). La actualidad de lo bello. Barcelona: Paidós.

Gasché, R. (1986). The tain of the mirror: Derrida and the philosophy of reflection. Harvard: Harvard University Press. 
El modelo sin modelo. El teatro en la filosofía de Jacques Derrida / Alejandro Fielbaum

(1994). Inventions of difference. Cambridge: Harvard University Press.

(1998). The Wild Card of Reading. On Paul de Man. Londres: Harvard University Press.

(1999). Re-presentations". En Of minimal things: Studies on the Notion of Relation. Stanford: Stanford University Press.

(2007). "Theatrum Theoreticum", en The Honor of thinking. Critique, Theory, Philosophy. Stanford: Stanford University Press.

Hall, S. (1999). "Identidad cultural y diáspora". En (Castro-Gómez, Santiago \& Guardiola-Rivera, Óscar \& Milán de Benavides, Carmen, Editores), Pensar en los intersticios. Teoría y práctica de la crítica poscolonial. Bogotá: Pontificia Universidad Javeriana.

Jay, M. (2007). Ojos abatidos: la denigración de la visión en el pensamiento francés del siglo XX. Madrid: Akal-

Johnson, C. (1996). "La lecon de philosophie: De Derrida à Lévi-Strauss". En (Lisse, Michel Director), Passiones de la littérature. Avec Jacques Derrida. París: Galilée.

Lacoue-Labarthe, P. (1997). "In the name of....". En (Lacoue-Labarthe, Philippe \& Nancy, Jean-Luc, Compiladores) Retreating the Political. Londres: Routledge.

(1998). Typography. Mimesis, Philosophy, Politicss. Stanford: Stanford University Press.

(2002). La ficción de lo político. Heidegger, el arte y la política. Madrid: Arena.

De Man, P. (1984). "Aesthetic Formalization: Kleist's Über das Marionettentheater". En Rethoric of Romanticism. New York: Columbia University Press.

(1990). "La lectura y la historia". En La resistencia a la teoría. Madrid: Visor.

(1991). "Crítica y crisis". En Visión y ceguera. Ensayos sobre la retórica de la contemporánea. Río Piedras: Ediciones de la Universidad de Puerto Rico.

Moreiras, A. (1999). Tercer espacio: Literatura y duelo en América Latina. Santiago: LOM.

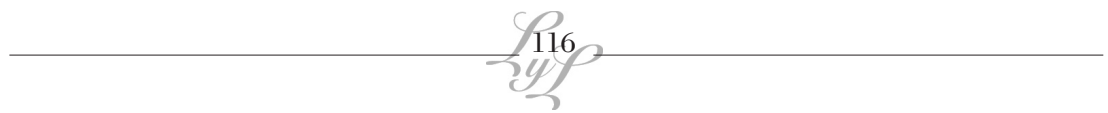


Nancy, J-L. (1999). "Foreword: Run, Sarah!”. En (Deutscher, Penelope \& Oliver, Kelly, Editores) Enigmas. Essays on Sarah Kofman. Nueva York: Cornell University Press.

(2002). Un pensamiento finito. Barcelona: Anthropos.

(2003). Corpus. Madrid: Arena.

(2007). "Mad Derrida: Ipso facto cogitans ac demens". En (Douzinas, Costas, Editor), Adieu Derrida. Nueva York: Palgrave Macmillan.

Peñalver, P. (1990). La desconstrucción. Escritura y filosofía. Barcelona: Montesinos.

De Peretti, C. (1989). Jacques Derrida: Texto y deconstrucción. Barcelona: Anthropos.

Stocker, B. (2006). Derrida on Deconstruction. Nueva York: Routledge.

Trujillo, I. (2005). "Coacción sin sujeto. En torno a Derrida y la razón inmunitaria". En Revista de la Academia nº10.

Weber, S. (2004). "Stages and Plots: Theatricality after September 11, 2001. A Discussion with Simon Morgan Wortham and Gary Hall”. En Theatricality as medium. Nueva York: Fordham University Press. 